Journal of History Culture and Art Research

Revue des Recherches en Histoire Culture et Art

مجلة البحوث التاريخية والثقافية و الفنية
Vol. 2, No. 2, June 2013

Copyright (C) Karabuk University

http://kutaksam.karabuk.edu.tr/index.php

Özel Sayı/Special Issue

(English Studies)

DOI: 10.7596/taksad.v2i2.247

\title{
Studying the poetry of Philip Larkin in the tertiary-level ELT \\ classroom: a twofold approach.
}

\section{Andy DIXON*}

\begin{abstract}
The paper explores the advantages gained from combining the thematic study of selected works of a significant poet - in this case Philip Larkin - and the exploitation of these works for the purpose of developing the four language skills. A detailed analysis of poems illustrative of the main themes of a particular poet's oeuvre not only provides opportunities for a wider understanding of his or her work than might be the case if the poet is being studied solely, as often occurs in tertiary-level classes, to demonstrate his or her historico-literary position and significance in the canon, but can also lead to numerous possibilities for language acquisition. As a by-product of a thematic approach, students will hopefully also be led to discover in the poetry areas of experience relevant to themselves, and this should, in turn, lead to reflection which will be given verbal or written expression. A selection of a poet's works, then, can usefully be read with a thematic focus in the context of a course in literature and simultaneously utilised as a language teaching and learning resource.
\end{abstract}

Keywords: Philip Larkin; ELT classroom; language skills; appreciation of poetry.

\footnotetext{
${ }^{*}$ University of Sussex, Lecturer in English Language and Literature.
} 


\section{Introduction}

Literature courses at tertiary level are frequently based on the analysis of a number of poems or pieces of prose taken from anthologies and selected to demonstrate the particular stylistic, philosophical, intellectual or emotional characteristics whereby a writer can be classified as belonging to a literary tradition or movement. Donne's Songs and Sonnets are used to show his reworking of the Elizabethan love lyric and his subversion of the Petrarchan convention. Metaphysical poetry in general can be contrasted with the fluidity and mellifluosness of the poetry it supersedes. The Lyrical Ballads in their eschewal of poetic diction and their choice of subject matter bring to an end the Neo-classical age and usher in Romanticism. Matthew Arnold's poetry testifies to the decline of the Romantic vision and foreshadows the sense of isolation and alienation that that will come to characterise much Modernist literature.

Whilst such an approach is certainly of some value (and inevitable in a historicoliterary style of course) students' knowledge of the range, diversity and thematic content of a writer's oeuvre is likely to remain somewhat limited and works come to be seen as examples of literary trends and fashions rather than as unique creations of the imagination, neglecting perhaps the fact that "[p]oetry relies...on the power of words, on their manifold suggestiveness" and that "it makes the greatest use of the raw material of literature, which is words" (Burgess 1974:7). It may also prove to be an unintentional invitation for students to lapse into the comfortably familiar role of uninvolved recipients of the instructor's interpretations.

Given, then, that tertiary-level students not infrequently need to be disabused of their "conception of a work as an achieved structure of meanings" (Abrams 1998: 231) and the notion, therefore, that their role in literature lessons is primarily a passive one, selection of texts demonstrating, as far as possible given time constraints, the range of a writer's poetic and imaginative concerns is of no little significance as opportunities should then present themselves for genuine engagement with texts, which will not necessarily exist if the poems are seen only as examples of work illustrating the style and assumptions of a literary period or trend. Furthermore, a concomitant gain will emerge in that students, when they are empowered to eschew the comforts of a teacher-orientated course and to genuinely engage with the text, will experience an enhanced opportunity for the development of analytical and interpretive skills and general literary and linguistic competence, which should be one of the primary objectives underpinning the course.

As far as poetry is concerned, a thematic approach has the potential to prove effective. One can take universal themes such as carpe diem, ageing and death, war and peace, nature, religious experience and relationships, as well as topical issues, such as environmental degradation, the increasing secularisation of western society, and the implications in the form 
of loneliness and isolation of the loss of a shared sense of community, and generate, even with reticent learners, meaningful interactions with the text. Poems are as Hall (1999:11) notes "a source of authentic language" characterised by "an unmistakeably individual voice", and should, if they are carefully chosen, strike a responsive chord in the consciousness of individual readers resulting not only in an expansion of their knowledge of a poet's range and treatment of particular themes, but also in high potential returns in terms of language awareness and development, for poetry can conveniently be used to the end of developing any or all of the four skills. Although literature courses are treated (rightly) as academic subjects, there would seem, nevertheless, to be no reason why they should not at the same time be used to foster acquisition. Literature as a course of study does not necessarily exclude what McRae (1991) terms "literature with a small 'l' ".

Indeed, in addition to the study of literature per se, there are many possibilities for using poems as a general resource in language learning. Pre-listening or pre-reading activities could include discussing personal experiences as a lead-in to the text, predicting content on the strength of the title using a grid or chart divided into probable, possible and unlikely sections, or inventing brief stories based on cue words from the poem. While-reading activities might make use of various cloze techniques or the selection of appropriate lexical items from a wordlist. Alternatively, students could be asked to assemble a short poem from jumbled lines or verses. And post-reading activities might involve writing a paraphrase or personal response, improving on a given but somewhat inaccurate paraphrase, or perhaps the students choosing the paraphrase that corresponds most closely to their response to the text from a list of three or four provided by the teacher. As a homework assignment students could be asked to write a short poem on any of the themes arising from the lesson or perhaps a "mini-story" of 50 to 60 words.

The author of the present paper proposes an approach to poetry through which students can concentrate on the major themes prevailing in the work of a particular poet. This allows the forming of a more inclusive picture of the poet's work than might otherwise be the case and facilitates the identification of his or her most typical contexts and concerns. Additionally, this provides a more holistic picture of a writer and at the same time offers students a chance to study in some detail a selection of poems. A session might begin with a warm-up in which the students are asked to look at a short poem from which the title has been removed and suggest their own titles. This could be followed by the teacher's brief introduction to the life, times and works of the poet. Next, students might be encouraged to compare certain selected poems to find common elements or themes and group them accordingly. Should any difficulties occur, assistance can be offered by the teacher's eliciting certain key words, such as time, loneliness, ageing, childhood, loss, disenchantment, and ask the students to discover how these are expressed in the poems. The following stage would be a discussion in pairs, groups or as a whole-class activity concentrating on an analysis of 
several of the poems or, time permitting, all of the selected works, concentrating on the themes that have been identified. By working on the texts in a structured way, focusing on a number of particularly relevant areas, the students should reach the point at which more general responses to the themes and issues will evolve and this is where the focus could change to the exploitation of the poems for language development purposes.

If post-Second World War poetry is under discussion, the work of Philip Larkin (1922 -1985) could usefully be considered as it lends itself conveniently to thematic categorisation. Larkin, was for a time in the 1950s and 60s associated with the loose grouping of writers known as the Movement, who were in reaction against what they perceived as the pretentiousness and cultural snobbery of earlier $20^{\text {th }}$-century literary groups such as Bloomsbury and the elitist stance of Modernism. Larkin occupies a somewhat unusual place in contemporary literature as a serious poet (rather than a lyricist) who enjoyed a certain popular appeal at the same time as experiencing considerable critical acclaim. It would be instructive in this context to enquire among students if this phenomenon of a connection between a degree of popular recognition and high poetic art is common in their cultures as it is unusual in contemporary Britain. And then, during the study of certain poems, students could perhaps be encouraged to enquire what are those aspects of Larkin's work that have endeared him to people who do not normally see themselves as readers of poetry.

A Larkin poem often begins in the particular, in ordinary incidents, occurrences or feelings which people can relate to - ambulances arriving at kerbsides, hospital visits, a sense of loneliness or loss - and these exert on him a need to preserve them as their implications and resonances have an abiding significance. In so doing, and by the use of a poetic idiom that is neither unduly obscure nor elitist, it might be argued that he succeeds in capturing the essence of contemporary Britain as it is experienced by many people. Life for Larkin, as David Timms (1973) has pointed out, is a condition in which the range possibilities is gradually being eroded and hopes of fulfilment end in disillusion. The Mr Bleaney of the eponymous poem may be Larkin looking at himself, but the feeling of not somehow having done with life what one might have done, of not having accomplished much, or indeed anything of note, is one that is common to many of his readers. But it is important, I think, to see Larkin's disillusionment with life, not so much as a sign of an almost pathological pessimism but as an aid to those wishing to come to terms with their own sense of disappointment. The poet in expressing succinctly and movingly what people may feel but struggle to articulate provides perhaps a sense of reassurance that they are not alone, that their uncertainties, doubts and fears are understood and indeed shared. There is an honesty about the work that helps people to endure life even if opportunities for enjoyment are few and become fewer with age. "To grow old is to be pushed to the side of your own life", remarks Christopher Ricks (1987: 279) alluding to the final two lines of "Afternoons". 
Larkin, then, could variously be described as the poet of the commonplace moment transformed, of the ordinary quotidian reality of the lives of the majority, of the sense of loss for which there is no compensation and, in Kirkham's words (1995: 284) as a poet for whom "reality is existence without man", but this would seem to be no disadvantage for an understanding of his work or for its exploitation as a linguistically rewarding classroom resource.

While the poetry can be seen as illustrating what Larkin saw as the unsatisfactoriness of life, subsumed within this general classification there exist a number of sub-themes which could be focused on. For example, old age, death and the futility of existence could be illustrated by "Ambulances", "The Building", "Aubade" and "The Old Fools"; love and its ramifications by "Wedding-Wind", "The Whitsun Weddings", "An Arundel Tomb", "High Windows", "Wild Oats", "This Be The Verse" and "Broadcast"; change for the worse by "MCMXIV" and "Going, Going"; recollections of childhood and home by "I Remember, I Remember"; "Reference Back", "Home is so Sad"; and general disillusionment, unfulfilment or loneliness by "Afternoons", "Annus Mirabilis", "Mr Bleaney", "Going", "Reasons for Attendance", "Vers de Societe" and "Breadfruit".

Larkin's poetry abounds with opportunities for language development, although lack of space precludes all but a brief mention and illustration of a number of possible activities. A useful lexical task involves providing students with ten sentences in which single gaps are required to be filled with ten words from a particular poem. Students could be asked to react to Larkin's pessimism by compiling lists of the factors that give their lives significance. The characteristics of and reasons for an optimistic or pessimistic attitude to life could be considered. And many of the poems could be used to stimulate discussion of topical issues such as pollution, ageism, euthanasia, the generation gap and the decline of religion in many western societies. In addition, one of more of his poems could be compared with thematically similar poems by other poets. If writing is a priority, major points from discussions could be utilised in five-paragraph-style essays.

Ultimately, it is important that the teacher, where necessary, plays the role of instructor, but by also functioning as "an intermediary between author, text and receiver" he or she will be engaged in "opening up a multi-directional sphere of interaction" (McRae, 1991:97). And, as Shu (1999: 26) points out, as a result of this shift from a "teacherknowledge approach to [a] participatory student-response approach, the meanings of literary texts become personal, through the spontaneous reaction and direct response of the learners" in conformity with the fundamental tenet of reader-response criticism "that displaces the notion of an autonomous text to be examined in and on its own terms from the centre of critical discussion and substitutes the reader's re-creation of the that text" (Brumfit and Benton: 1995: 2). 
Finally, all techniques and strategies employed by teachers to empower students to assume responsibility for their own learning and "to grapple with the text and its language and to relate it to the values and traditions of their own society" (Lazar, 1993:19) will be of benefit in what, at least in Europe, is rapidly becoming the unfashionable pursuit of educating the whole person. A thematic approach to poetry which leads to a further consideration of those areas of experience encountered in the poems through involving students in activities which they will regard as relevant to their own lives would seem, more than most approaches, to further that end.

\section{References}

Thwaite, A. (ed.) (2003). Philip Larkin: Collected Poems. London: Faber and Faber.

Abrams, M.H. (1988). A Glossary of Literary Terms. New York: Harcourt, Brace, Jovanovic College Publishers.

Brumfit, C. and Benton, M. (1995). Teaching Literature: A World Perspective. Hemel Hempstead: Phoenix ELT.

Burgess, A. (1974). English Literature. Harlow: Longman.

Ford, B. (ed.) (1995). The New Pelican Guide to English Literature, Vol. 8. London: Penguin.

Hall, G. (1999). Talking about Literature. Modern English Teacher, 8,3: pp. 11-14. Lazar, G. 1993. Literature and Language Teaching. Cambridge: Cambridge University Press. Kirkham, M. 1995. Philip Larkin and Charles Tomlinson: Realism and Art. In Ford, B. (ed.) pp. 284304.

McRae, J. (1991). Literature with a small " $l$ ". Basingstoke and London: Macmillan.

Ricks, C. (1987). The Force of Poetry. Oxford: Oxford University Press.

Timms, D. (1973). Philip Larkin. Edinburgh: Oliver and Boyd.

Shu, W. (1999). Literature Teaching. English Teaching Forum. Vol. 37,3: pp 25-27. 


\section{Appendix: a selection of sample exercises.}

\section{The Old Fools}

Follow the text of "The Old Fools" while listening to the tape recording of Philip Larkin reading the poem. If the tape is not available, your teacher will read the poem. What is your reaction to "The Old Fools"?

What do they think has happened, the old fools,

To make them like this? Do they somehow suppose

It's more grown-up when your mouth hangs open and drools,

And you keep on pissing yourself, and can't remember

Who called this morning? Or that, if they only chose,

They could alter things back to when they danced all night,

Or went to their wedding, or sloped arms some September?

Or do they fancy there's really been no change,

And they've always behaved as if they were crippled or tight,

Or sat through days of thin continuous dreaming

Watching light move? If they don't (and they can't), it's strange:

Why aren't they screaming?

At death you break up: the bits that were you

Start speeding away from each other for ever

With no one to see. It's only oblivion, true:

We had it before, but then it was going to end,

And was all the time merging with a unique endeavour

To bring to bloom the million-petalled flower

Of being here. Next time you can't pretend

They'll be anything else. And these are the first signs:

Not knowing how, not hearing who, the power

Of choosing gone. Their looks show that they're for it:

Ash hair, toad hands, prune face dried into lines -

How can they ignore it?

Perhaps being old is having lighted rooms

Inside your head, and people in them, acting.

People you know, yet can't quite name; each looms

Like a deep loss restored, from known doors turning,

Setting down a lamp, smiling from a stair, extracting 
A known book from the shelves; or sometimes only

The rooms themselves, chairs and a fire burning,

The blown bush at the window, or the sun's

Faint friendliness on the wall some lonely

Rain-ceased midsummer evening. That is where they live:

Not here and now, but where all happened once.

This is why they give

An air of baffled absence, trying to be there

Yet being here. For the rooms grow farther, leaving

Incompetent cold, the constant wear and tear

Of taken breath, and them crouching below

Extinction's alp, the old fools, never perceiving

How near it is. This must be what keeps them quiet:

The peak that stays in view wherever we go

For them is rising ground. Can they never tell

What is dragging them back, and how it will end? Not at night?

Not when the strangers come? Never, throughout

The whole hideous inverted childhood? Well,

We shall find out.

Which of the following summaries is closest to your own response to the poem?

A. The poem is a literal account of what Larkin in one of his novels calls the "grotesque and caricaturing effects of age". There is very little in the poem that is uplifting apart from possibly - the flower image in lines 18-20. Larkin seems to lack any sympathy or compassion for the predicament of the elderly. The honesty of the poem borders on the cruel.

B. Larkin's poem invites a certain stoicism in the face of physical and mental decline. It is about senility, about the inability of some elderly people to comprehend what is happening to them, and this provokes anger in the poet - anger that the human condition condemns people to be shadows of their former selves as they approach death. "The Old Fools" is pervaded by a sense of bitterness.

C. "The Old Fools" deals at some length with the exterior appearance of the elderly and with the effects of senility without lapsing into the sentimentality that characterises many poems 
about old age. The tone appears callous - cruel even - but in the final stanza the reader is made aware that Larkin is not without a degree of sympathetic understanding of these people's plight because he knows that one day he will probably be like them. The poem is not so much a call to stoicism as a statement of resignation.

Below is a poem about old age by the poet Adrian Mitchell (1932-2008). Compare and contrast it with "The Old

Fools". Which poem do you prefer? Why?

\section{Old Age Report}

When a man's too ill or old to work

We punish him.

Half his income is taken away

Or all of it vanishes and he gets pocket money.

We should reward these tough old humans for surviving,

Not with a manager's soggy handshake

Or a medal shaped like an alarm clock -

No, make them a bit rich,

Give the freedom they always heard about

When the bloody chips were down

And the blitz or the desert

Swallowed their friends

Retire, retire into a fungus basement

Where nothing moves except the draught

And the light and dark grey figures

Doubling their money on the screen;

Where the cabbages taste like the mummy's hand

And the meat tastes of feet;

Where there is nothing to say except:

"Remember?" or "Your turn to dust the cat".

To hell with retiring. Let them advance.

Give them the money they've always earned

Or more - and let them choose. 
If Mr Burley wants to be a miser,

Great, let the moneybags sway and clink for him,

Pay him a pillowful of best doubloons.

So Mrs Wells has always longed to travel?

Print her a season ticket to the universe,

Let her slum-white skin

Be tanned by a dozen different planets.

We could wipe away some of their worry,

Some of their pain - what I mean

Is so bloody simple:

The old people are being robbed

And punished and we ought

To be letting them out of their cages

Into green spaces of enchanting light.

\section{Points for discussion.}

(i) In countries such as Britain the provision of so-called residential homes (also referred to as care homes or nursing homes) has become a kind of industry. What do you think about this?

(ii) Is encouraging elderly family members to live in a retirement home a way of abandoning them?

(iii) Are there any advantages to living in a retirement home for elderly people?

(iv) At what age do people in your country retire? In many European countries women are allowed to retire earlier than men. As women's life expectancy is longer than men's, is this fair?

(v) In certain countries, such as China, it is customary for political leaders to be fairly advanced in years. Is this a good idea? Do elderly people make better leaders than younger people?

(vi) In Britain a recent survey concerning retirement found that when young people (under 30) were asked about when ideally they would like to retire, a high percentage of them answered 50. However, when people between 50 and 60 were questioned, many of them said that they would like to go on working for as long as possible. How do you account for this?

(vii) Rather than having a fixed retirement age, should pensions become available only after a 
person has worked a certain number of years?

(viii) As people live longer and birth rates fall, particularly in Europe, many countries are heading towards a situation where elderly people will far outnumber younger people.

Will the fact of ageing populations be a problem?

(ix) Have you come across the neologisms "ageism" and "ageist". What do they refer to?

(x) Is it your impression that families in Turkey are closer than those in many parts of Europe?

\section{Ambulances}

Six words have been removed from the poem and placed in random order beneath it. Can you restore them to their correct positions?

Closed like confessionals, they thread

Loud noons of cities, giving back

None of the they absorb.

Light glossy grey, arms on a plaque,

They come to rest at any kerb:

All streets in time are visited.

Then children strewn on steps or road,

Or women coming from the shops

Past smells of different dinners, see

A wild white that overtops

Red stretcher-blankets momently

As it is carried in and stowed,

And sense the solving emptiness

That lies just under all we do,

And for a second get it whole,

So and blank and

The fastened doors recede. Poor soul,

They whisper at their own distress;

For borne away in deadened air

May go the sudden shut of loss

Round something nearly at an end, 
And what cohered in it across

The years, the random blend

Of families and fashions, there

At last begin to loosen. Far

From the exchange of to lie

Unreachable inside a room

The traffic parts to let go by

Brings closer what is left to come,

And dulls to distance all we are.

permanent unique glances love face true

\section{Questions:}

1. What does the poet mean by "All streets in time are visited" when referring to ambulances?

2. What is the significance of the word "stowed" at the end of the second stanza?

3. What are the people witnessing the scene momentarily aware of?

4. "Poor soul/They whisper at their own distress." Why "at their own distress"?

5. What is "nearly at an end" in the fourth stanza?

6. What is the significance of the word "unique" in the fourth stanza?

7. How does the poet envisage the patient's experience of hospital?

8. Reflecting on this man's demise, what does Larkin suggest about life in general?

9. Is the poem depressing, do you think?

10. Make a list of all the things that give meaning and value to your life. 


\section{Annus Mirabilis}

Sexual intercourse began

In nineteen sixty-three

(Which was rather late for me) -

Between the end of the Chatterley ban

And the Beatles' first LP.

Up till then there'd only been

A sort of bargaining,

A wrangle for a ring,

A shame that started at sixteen

And spread to everything.

The all at once the quarrel sank:

Everyone felt the same,

And every life became

A brilliant breaking of the bank,

A quite unlosable game.

So life was never better than

In nineteen sixty-three

(Though just too late for me) -

Between the end of the Chatterley ban And the Beatles' first LP.

\section{High Windows}

When I see a couple of kids

And guess he's fucking her and she's

Taking pills or wearing a diaphragm,

I know this is paradise

Everyone old has dreamed of all their lives -

Bonds and gestures pushed to one side

Like an outdated combine harvester,

And everyone young going down the long slide

To happiness, endlessly. I wonder if

Anyone looked at me, forty years back,

And thought, That'll be the life;

No God any more, or sweating in the dark

About hell and that, or having to hide

What you think of the priest. He

And his lot will all go down the long slide

Like free bloody birds. And immediately

Rather than words comes the thought of high

windows:

The sun-comprehending glass,

And beyond it, the deep blue air, that shows

Nothing, and is nowhere, and is endless.

a. Which short summary of "Annus Mirabilis" is closest to your reading of the poem?

1. The poet begins by seemingly regretting that he missed out on the sexual revolution of the Sixties. The irony is directed at himself. However, by the end of the poem it is redirected at a generation which was perhaps mistaken in thinking it had made a major breakthrough. "So life was never better than/In nineteen sixty-three" suggests that society has not subsequently benefited from the changes that occurred in relationships in the Sixties. 
2. The poem is about the generation gap. The poet is in a state of regret that he was unable to benefit from the change in sexual mores that occurred in the early 1960s. He is of the generation of the previous decade which felt shame about relationships. He has not been able to participate in the "quite unlosable game".

b. Explain the irony at the end of the first stanza and the beginning of the second.

c. What did the poet's generation get rid of when they were young?

d. What taboo has the present generation dispensed with?

e. Is the poet suggesting that the young in their rebellion against the values of their parents' generation are less free than they imagine themselves to be?

f. Does Larkin give the reader any indication of what true freedom is?

g. Larkin's social conservatism has been well documented. Read "Going, Going". In this poem what is Larkin concerned about? What does he fear? Is he exaggerating? Is the poem the outpourings of a bitter, elderly man or do you share his concern?

h. Are you optimistic about the future or are you pessimistic? Give reasons for your answer.

i. Do you consider yourself to be free?

\section{Creative Writing Exercises}

Read "Reference Back", a work in which the speaker, a man in his early thirties, looks back on his "unsatisfactory" childhood and considers his "unsatisfactory prime". Then read "Home Is So Sad' below. Write a short poem (about six lines, rhymed or unrhymed, on the theme of home or childhood.

\section{$\underline{\text { Home Is So Sad }}$}

Home is so sad. It stays as it was left, Shaped to the comfort of the last to go As if to win them back. Instead, bereft of anyone to please, it withers so, Having no heart to put aside the theft

And turn again to what it started as,

A joyous shot at how things ought to be,

Long fallen wide. You can see how it was:

Look at the pictures and the cutlery.

The music in the piano stool. That vase. 
Here is an uncollected quatrain by Larkin entitled "1952-1977", written in 1978. To whom do you think the stanza refers? The dates are significant. Write a four-line verse about someone, living or dead, famous or unknown, you admire.

\section{$\underline{1952-1977}$}

In times when nothing stood

but worsened, or grew strange,

there was one constant good:

she did not change. 